\title{
Comparative studies exhaust emissions of the Euro VI buses with diesel engine and spark-ignition engine CNG fuelled in real traffic conditions
}

\author{
Maciej Gis ${ }^{1, *}$ \\ ${ }^{1}$ Motor Transport Institute, ul. Jagiellonska 80, 03-301 Warsaw, Poland
}

\begin{abstract}
You should leave $8 \mathrm{~mm}$ of space above the abstract and $10 \mathrm{~mm}$ after the abstract. The heading Abstract should be typed in bold 9-point Times. The body of the abstract should be typed in normal 9-point Arial in a single paragraph, immediately following the heading. The text should be set to 1 line spacing. The abstract should be centred across the page, indented $17 \mathrm{~mm}$ from the left and right page margins and justified. It should not normally exceed 200 words.
\end{abstract}

\section{Introduction}

Air pollution coupled with more and more restrictive requirements concerning the emission of hazardous exhaust gases cause that bus fleets in towns and also in non-urban traffic are changing considerably. In large urban areas the content of hazardous substances usually exceeds standard levels. Kraków is the best example. In October 2016 year once again an alert was announced that admissible PM10 levels exceeded. One of the measurement station recorded $61 \mu \mathrm{g} / \mathrm{m}^{3}$ at 10 am and $127 \mu \mathrm{g} / \mathrm{m}^{3}$ at $1 \mathrm{am}$. In Nowa Huta a level of $50 \mu \mathrm{g} / \mathrm{m}^{3}$ was observed at $9 \mathrm{am}$ and $63 \mu \mathrm{g} / \mathrm{m}^{3}$ at $1 \mathrm{am}$. The firstdegree alerts were also announced in Warsaw. According to public alerts admissible levels for air quality as regards benzo(a)pyrene were most likely exceeded in the entire Mazowieckie region, and in some towns and communities also for $\mathrm{PM}_{10}$ and $\mathrm{PM}_{2.5}$ and nitrogen dioxide. To counteract the above motor vehicle companies are launching new technical solutions. One of the possibilities as regards vehicles is to replace traditional city fleets with vehicles powered by alternative systems [1]. Another method of reducing emission of hazardous exhaust gases to atmosphere comprises actions aimed at limiting traffic of passenger cars by opting for public transport, e.g. by intensifying actions promoting and improving the public transportation infrastructure [2].

\section{European requirements regarding emission of hazardous substances by buses}

The main element that has impact on the construction of buses and allows for their sale are requirements concerning the reduction of exhaust emissions. Because of environmental requirements actions are undertaken to reduce to maximum degree the emission of toxic substances of exhaust gases, in particular the emission of nitrogen oxides $-\mathrm{NO}_{\mathrm{X}}$, hydrocarbons $-\mathrm{HC}$, carbon oxides - CO, PM and PN [3, 4].

Those requirements are laid down in international and European standards on the level of exhaust emissions from Euro $\mathrm{V}$ and $\mathrm{EEV}$, i.e. vehicles particularly environmentally friendly - regulations with effect as from 2009 and implemented by way of Directive 2005/55/EC of 28 September 2005 [5]. Starting from 2014 the new Euro VI standard is in force, as set forth in Regulation no. 595/2009 [6] and in the EEV standard. In real conditions of traffic the values of admissible emissions may be exceeded for instance for $\mathrm{CO} . \mathrm{HC}$ and $\mathrm{NO}_{\mathrm{X}} 1.5$ times [7] (Regulation no. 582/2011 EC [8]).

For conventional SI engines to be able to fulfil the standards of exhaust emissions, SCR (Selective Catalytic Reduction) must be applied. SCR acts by converting hazardous substances in exhaust gases from SI engines in the discharge, in particular nitrogen oxides and their transformation into vapour and neutral nitrogen. The transformation is effected in the presence of non-toxic aqueous urea solution AdBlue ${ }^{\circledR}$ as catalyst of exhaust gases. The electronic system of engine management

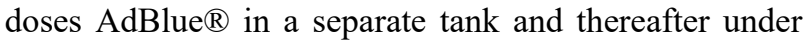
high pressure is injected directly to the reactor, where AdBlue ${ }^{\circledR}$ reacts with ammonia and decomposes into nitrogen and water vapour. Owing to this technology fuel consumption is reduced by approx. 5\% [9] and the emission of nitrogen oxides $\left(\mathrm{NO}_{\mathrm{X}}\right)$ is reduced and also reduced - even more - is the emission of particulate matter. It is estimated that approx. $1,7 \mathrm{dm}^{3}$ of AdBlue ${ }^{\circledR}$ is required per $100 \mathrm{~km}$ (in case of vehicles with Euro V emission levels) $[10,11]$. 


\section{Buses fuelled with CNG}

Methane is the main constituent of natural gas, with volume ranging from 90 to $98 \%$. The remaining constituents include in particular ethane, propane, butane and nitrogen. Natural gas used typically in a compressed form characterises with low energy density. Under pressure of $17.7 \mathrm{MPa}$ and in a temperature of $21{ }^{\circ} \mathrm{C}$ it is equal to $7 \mathrm{~kJ} / \mathrm{cm}^{3}$ (which is $30 \mathrm{~kJ} / \mathrm{cm}^{3}$ for petrol). Due to a much lower density of gas fuels and in consequence lower energy per volume unit the vehicle must be specially adapted to gas fuelling. Effective use of energy contained in gas fuel necessitates changes in the power unit $[12,13]$.

\section{The purpose and scope of the study}

The purpose of the studies was to estimate the emission properties and fuel consumption of public transport buses fuelled by CNG and diesel fuel. The test route was selected at random and in two towns $\mathrm{A}$ and $\mathrm{B}$ along the road between them. CNG-fuelled bus was an articulated bus equipped with an internal combustion engine fulfilling the Euro VI emission standard. The bus production year was 2015 and its engine displacement was equal to $12816 \mathrm{~cm}^{3}$, with power of $228 \mathrm{~kW}$. The diesel-fuelled bus was also an articulated bus with engine displacement of $10,518 \mathrm{~cm}^{3}$ and maximum power of $235 \mathrm{~kW}$, and production year 2015 .

The studies were conducted during one day. Fig. 1 presents the tested buses with the installed testing equipment.

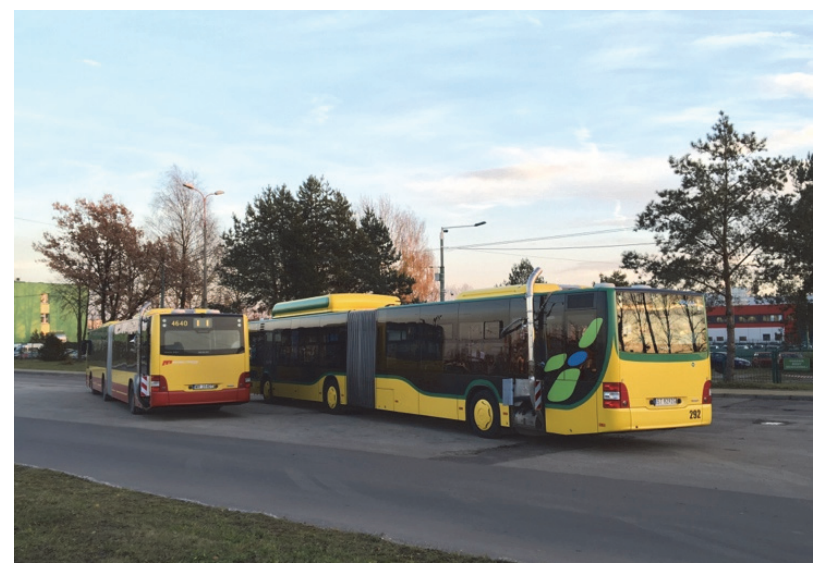

Fig. 1. Tested buses with the testing equipment (CNGfuelled bus and diesel oil bus).

Testing equipment - PEMS used in the studies is presented in Fig. 2. Two mobile analysers Semtech DS were used to measure the content of hazardous compounds in exhaust gases [14]. The equipment was used to measure compounds of harmful exhaust gases, i.e. carbon dioxide, carbon oxide, hydrocarbons and nitrogen oxides and to assess fuel consumption with the carbon balance method. Information in publications regarding the use of mobile exhaust gas analysers coupled with data recorded by on-board diagnostic systems $[6,15]$, prove that the evaluation of contamination emission in real conditions of traffic with the use of such equipment was reasonable.

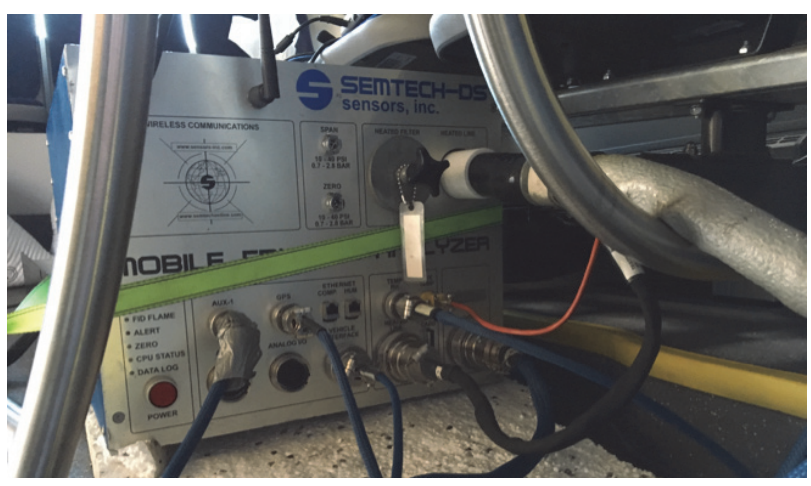

Fig. 2. PEMS testing equipment.

\section{Research methodology}

The exhaust gases emission and fuel consumption had been measured in a range of driving conditions. The emission of hazardous exhaust substances and fuel consumption were compared owing to measurements made with two devices. Both vehicles moved one after another, which allowed for eliminating errors due to driving style or changeable weather conditions. The test route combined elements of urban and country driving (Fig. 3 and 4). Parameters of the test route are represented in Table 1.

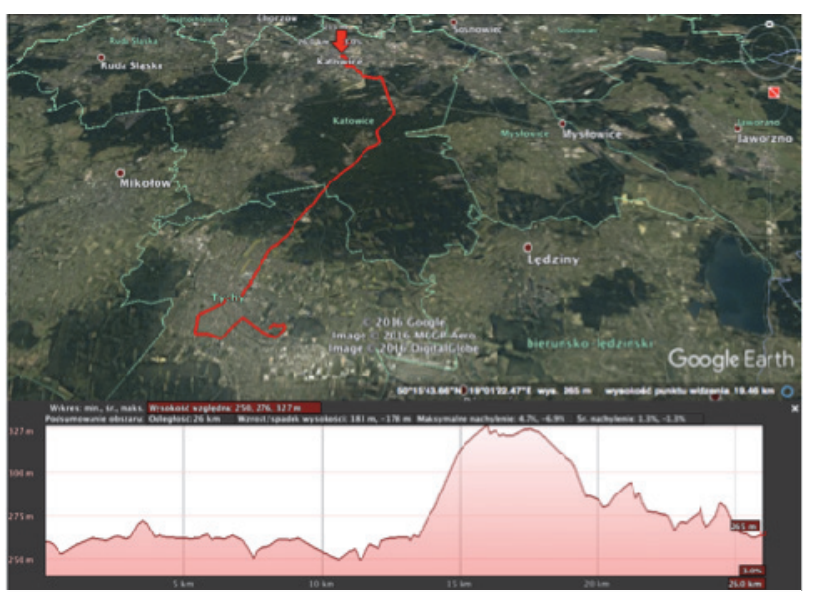

Fig. 3. Characteristics of the test rote.

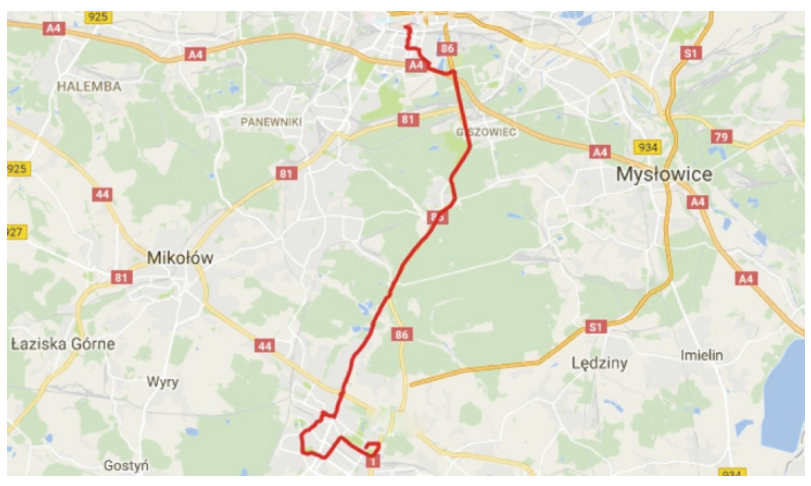

Fig. 4. Test route. 
Table 1. Parameters of the test route.

\begin{tabular}{|l|c|}
\hline Length & $26 \mathrm{~km}$ \\
\hline Change of altitude & $\min : 183 \mathrm{~m}, \max : 178 \mathrm{~m}$ \\
\hline Max. slope & $4.7 \%$ \\
\hline Min. slope & $-6.9 \%$ \\
\hline Average positive slope & $1.3 \%$ \\
\hline Average negative slope & $-1.3 \%$ \\
\hline
\end{tabular}

\section{Results and analyses of studies}

The results of studies could be evaluated owing to a positive result of the comparison of test routes and their large time consistency. This is because the portion of time of vehicle's driving phases was determined in the test (with values rounded to full units). The compared values for acceleration, fixed velocity, braking and stopover of vehicles are presented below.

Table 2. Values of respective driving phases of tested buses.

\begin{tabular}{|l|c|c|c|}
\hline & Value & $\begin{array}{c}\text { Bus powered } \\
\text { by CNG fuel }\end{array}$ & $\begin{array}{c}\text { Bus powered } \\
\text { by diesel fuel }\end{array}$ \\
\hline Acceleration & $\%$ & 38 & 40 \\
\hline Fixed velocity & $\%$ & 19 & 9 \\
\hline Braking & $\%$ & 28 & 35 \\
\hline Stopover & $\%$ & 15 & 17 \\
\hline
\end{tabular}

With the test results, it was possible to determine the content and intensity of flow, depending on the route. Fig. 5 presents the results for $\mathrm{CO}_{2}$ with reference to the road, for both tested buses.
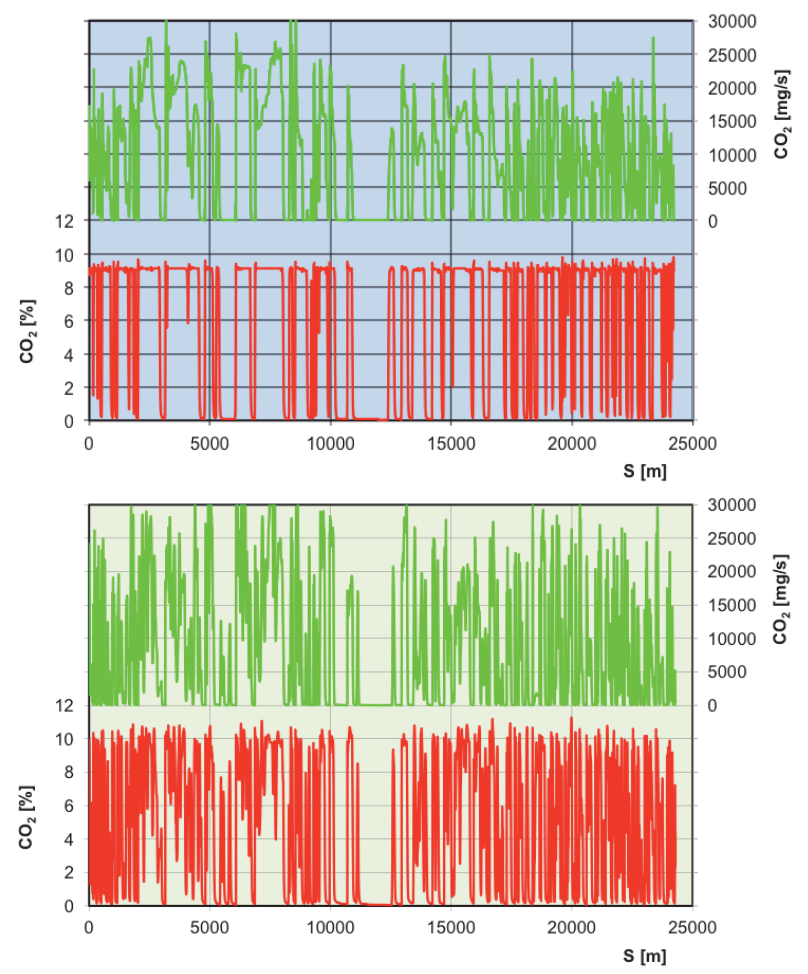

Fig. 5. Concentration and intensity of $\mathrm{CO}_{2}$ emission with reference to the completed road: - I bus (CNG-fuelled), - II bus (diesel fuelled).
Fig. 6 presents temporary and average fuel consumption, also with reference to the route of both vehicles.
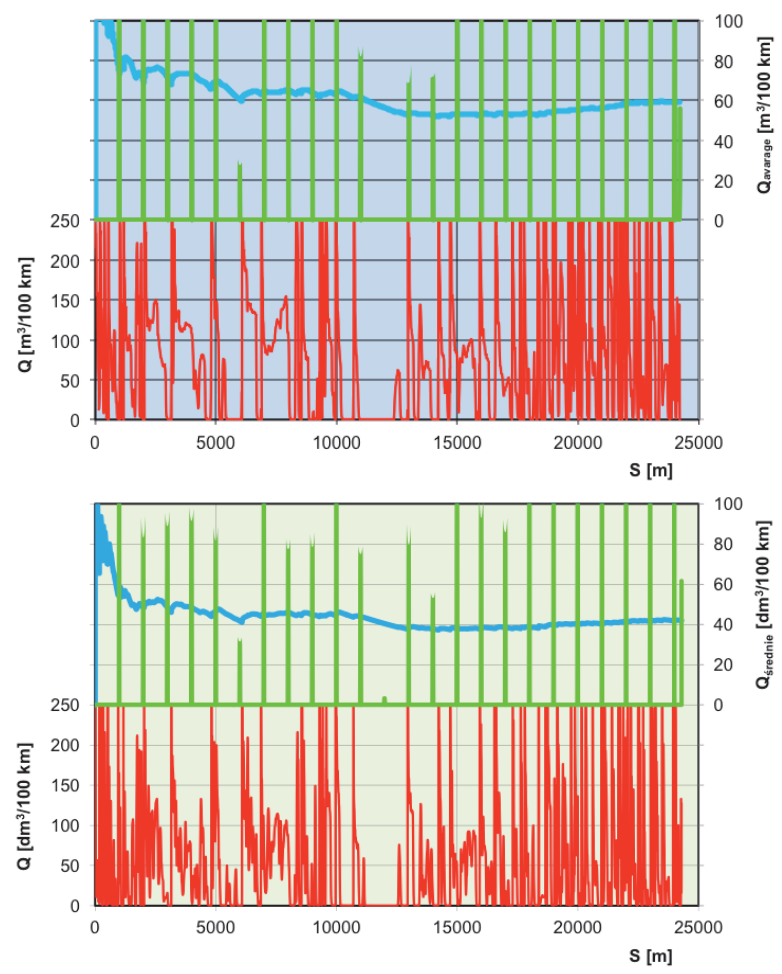

Fig. 6. Characteristics of temporary and average fuel consumption with reference to the completed road: - I bus (CNG-fuelled), - II bus (diesel fuelled).

Owing to the tests it was possible to determine time courses for the intensity of emission of hazardous substances of exhaust gases for both buses. Hense, correlations were developed characterising the impact of dynamic properties of public transport buses on the emission of harmful compounds. Dynamic properties of vehicles were included indirectly, using the entire velocity range and the range of mesured acceleration in urban traffic for a matrix of intensity of emissions of respective pollutants. Those figures were averaged in respective velocity and acceleration ranges.

Therefore, characteristics of operation in respective ranges and the matrix of emission of harmful compunds had been determined. According to data presented in Fig. 7 there is a similarity in the portion of operating time for the tested buses. Also, a greater portion of operation is observed in the area of minimum driving speed (stopover) and high driving speeds (10-18 m/s) and zero bus acceleration.

Two-dimensional histogram of intensity of $\mathrm{CO}_{2}$ emission $[\mathrm{mg} / \mathrm{s}]$ in the relation velocity - acceleration is presented in Fig. 8. It represented indirectly the fuel consumption during the tests. The bus fuelled with $\mathrm{CNG}$ was comparable. Histograms of intensity of $\mathrm{CO}_{2}$ emission during the tests for averaged velocities are represented in Fig. 9. 

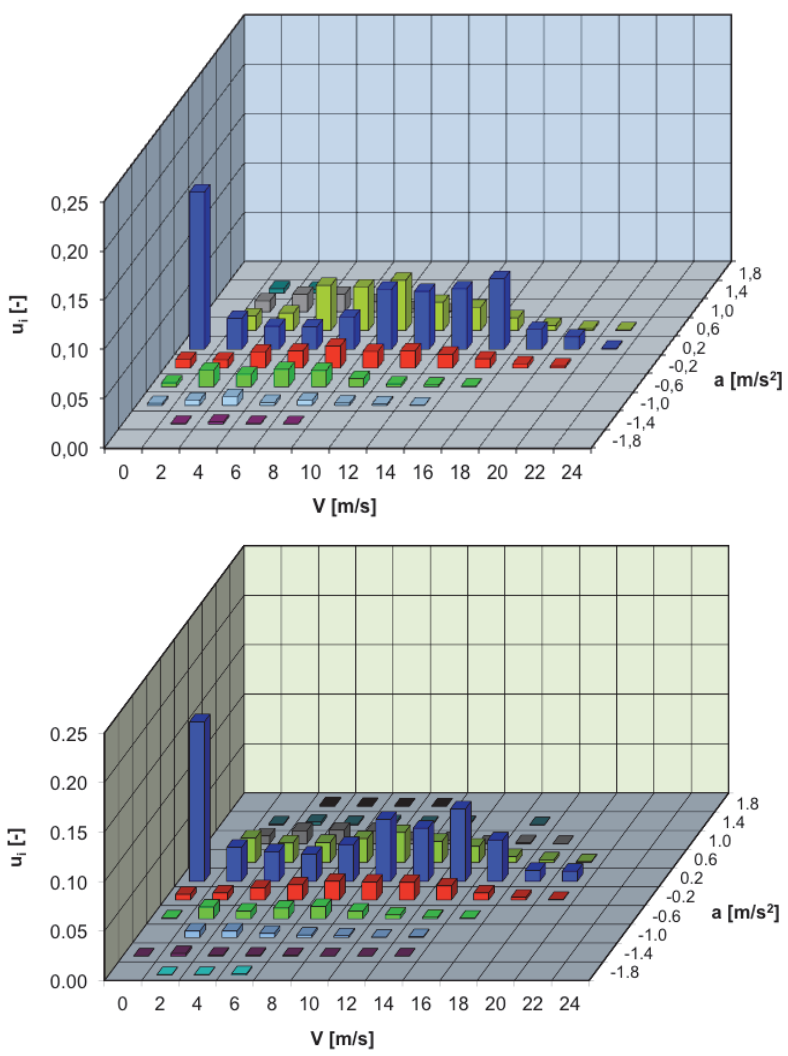

Fig. 7. Two-dimensional histograms of vehicle's operating time in relation velocity - acceleration: - I bus (CNGfuelled), - II bus (diesel fuelled).
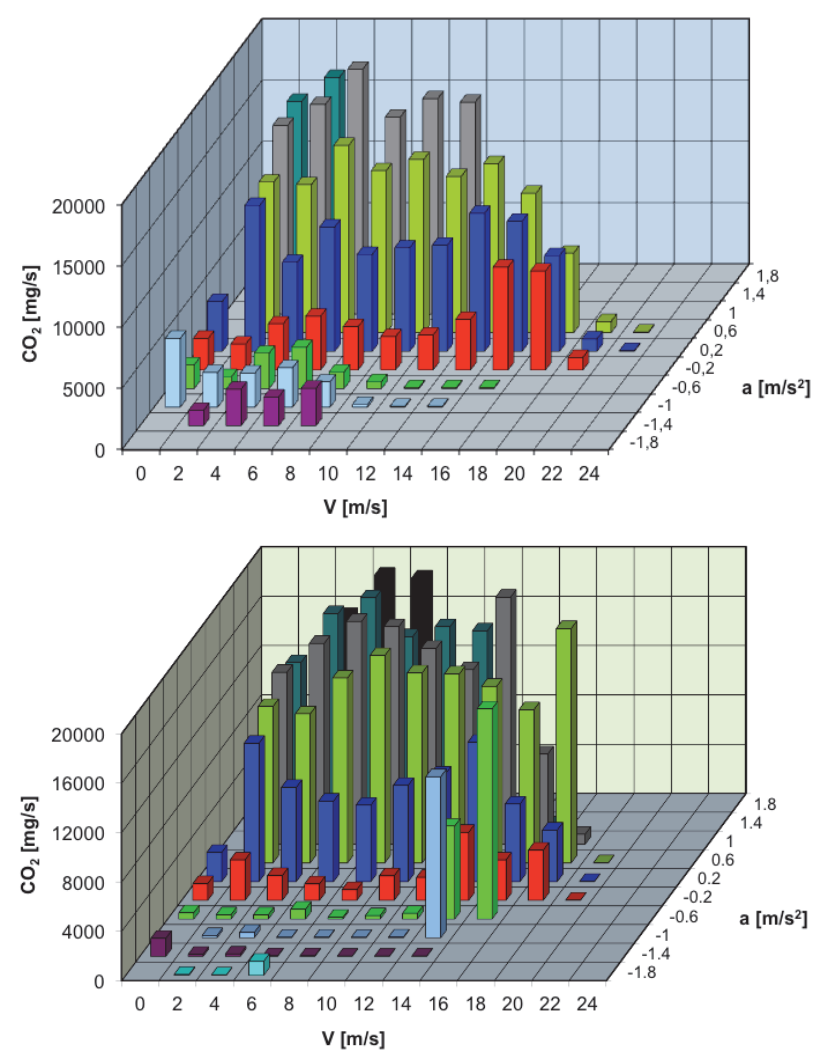

Fig. 8. Two-dimensional histograms of $\mathrm{CO}_{2}$ emission intensity during the tests in relation velocity - acceleration: - I bus (CNG-fuelled), - II bus (diesel fuelled).
In case of the CNG-fuelled bus, attention must be given to $\mathrm{NO}_{\mathrm{X}}$ emission, which is lesser than in the diesel-fuelled bus. Fig. 10 presents a two-dimensional histogram of $\mathrm{NO}_{\mathrm{x}}$ emission intensity during the tests in the relation velocity - acceleration. The figures shown in Fig. 10 prove the above.
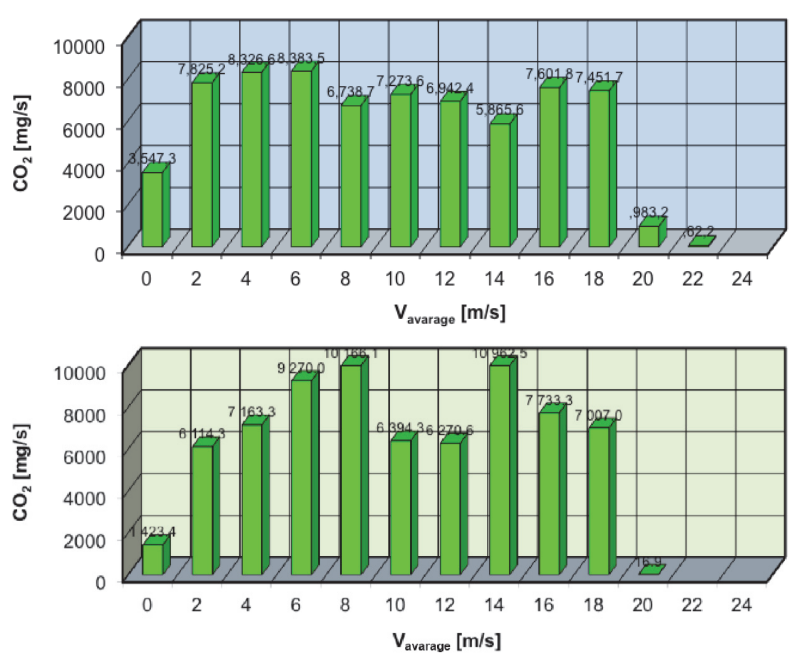

Fig. 9. Histograms of $\mathrm{CO}_{2}$ emission intensity during the tests for average velocity: - I bus (CNG-fuelled), - II bus (diesel fuelled).
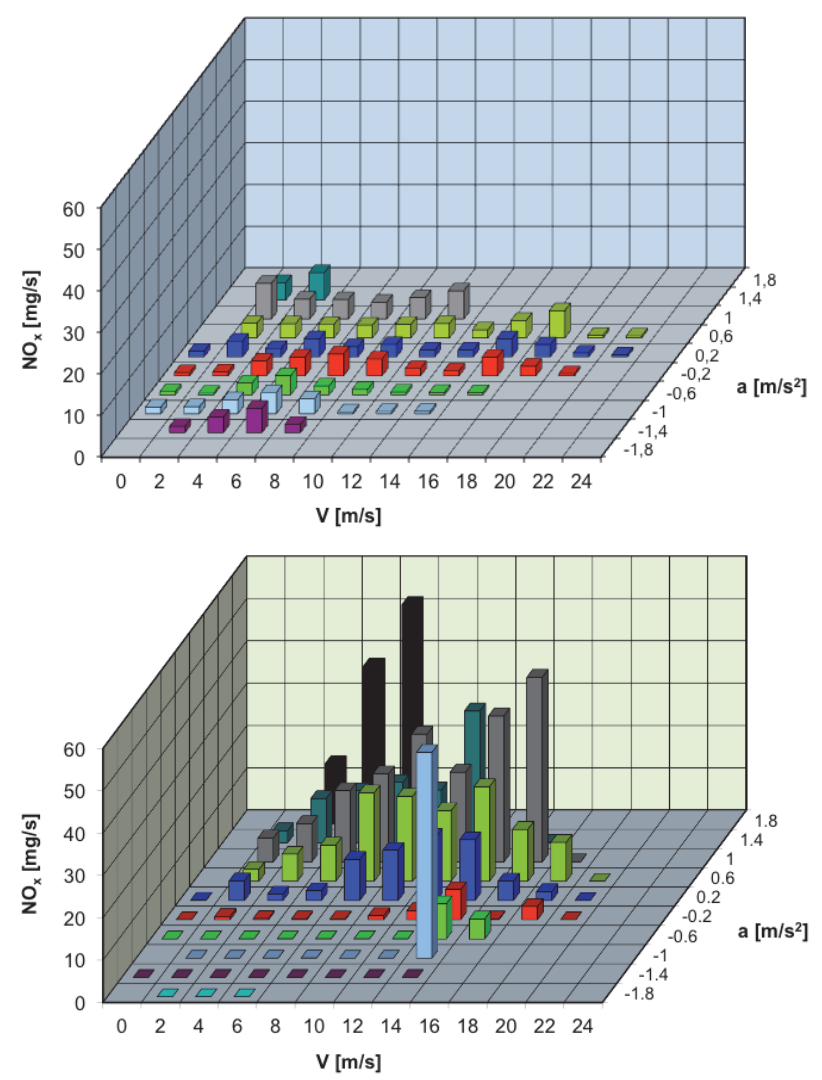

Fig. 10. Two-dimensional histograms of NOx emission intensity during the tests in relation velocity - acceleration: - I bus (CNG-fuelled), - II bus (diesel fuelled). 
Also, in case of $\mathrm{HC}$ emission intensity, the CNGfuelled bus manifests lower emission than the dieselfuelled bus. This is reflected in Fig. 11 and corroborated as in Fig. 12.
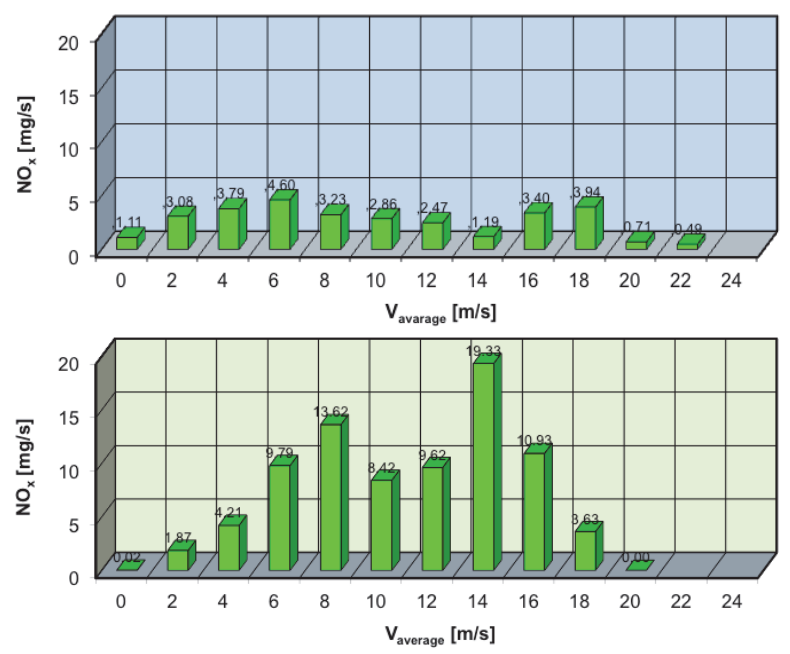

Fig. 11. Histograms of NOx emission intensity during the tests for average velocity: - I bus (CNG-fuelled), - II bus (diesel fuelled).
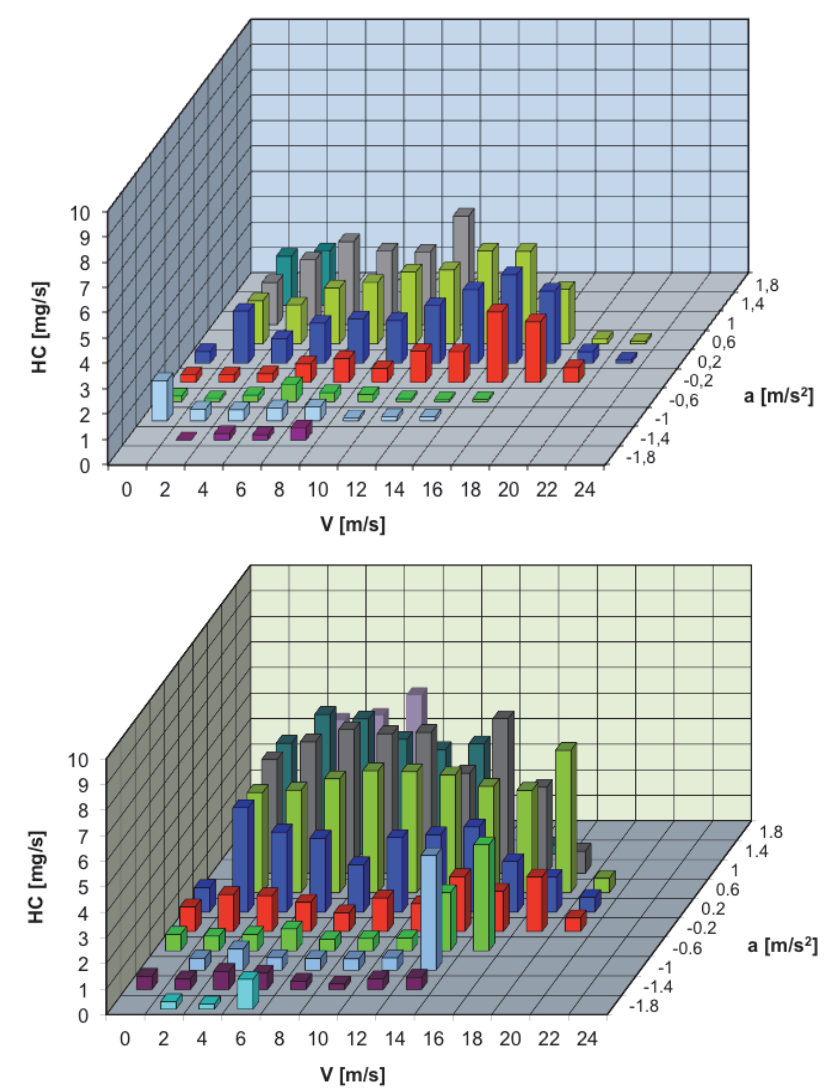

Fig. 12. Two-dimensional histograms of hydrocarbons emission intensity during the tests in relation velocity acceleration: - I bus (CNG-fuelled), - II bus (diesel fuelled).
On Fig. 13 and Fig. 14 are presents the results of fuel consumption and road emission of exhaust gases in the course of tests and a comparison of fuel consumption and exhaust emissions during tests.
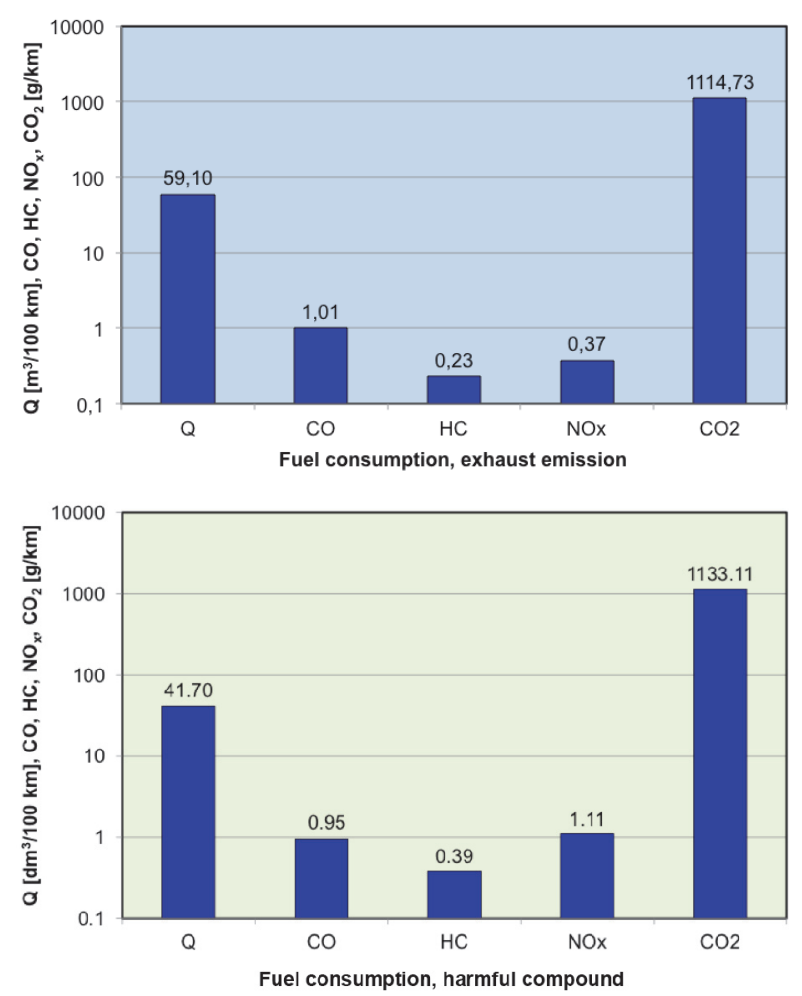

Fig. 13. Results of fuel consumption and road emission of exhaust gases during tests: - I bus (CNG-fuelled), - II bus (diesel fuelled).

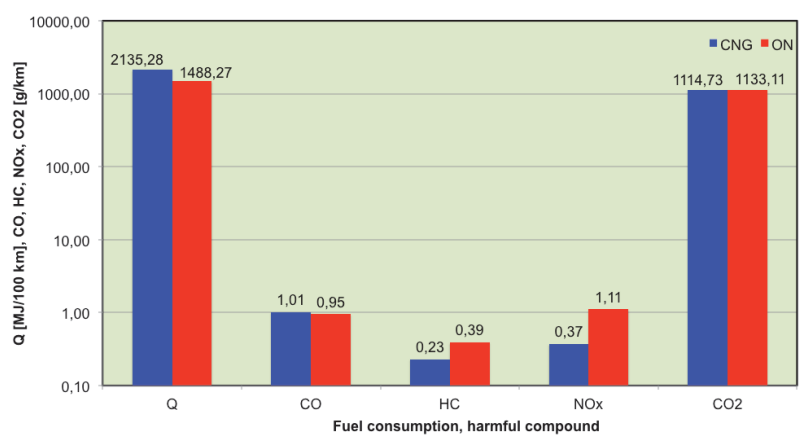

Fig. 14.Comparison of fuel consumption and emission of exhaust gases during tests: - I bus (CNG-fuelled), - II bus (diesel fuelled).

\section{Summary}

The tests in real road traffic conditions resulted in the following conclusions:

- consumption (natural gas) $59,1 \mathrm{~m}^{3} / 100 \mathrm{~km}$ (CNGfuelled bus) and $41.7 \mathrm{dm}^{3} / 100 \mathrm{~km}$ (diesel-fuelled bus),

- CO emission: $1.01 \mathrm{~g} / \mathrm{km}$ (CNG-fuelled bus) and 0.95 $\mathrm{g} / \mathrm{km}$ (diesel-fuelled bus),

- HC emission: $0.23 \mathrm{~g} / \mathrm{km}$ (CNG-fuelled bus) and 0.39 $\mathrm{g} / \mathrm{km}$ (diesel-fuelled bus), 
- $\mathrm{NO}_{\mathrm{X}}$ emission: $0.37 \mathrm{~g} / \mathrm{km}$ (CNG-fuelled bus) and $1.11 \mathrm{~g} / \mathrm{km}$ (diesel-fuelled bus),

- $\mathrm{CO}_{2}$ emission: $1114,73 \mathrm{~g} / \mathrm{km}$ (CNG-fuelled bus) and $1133,11 \mathrm{~g} / \mathrm{km}$ (diesel-fuelled bus).

Attention should be given to the fact that despite positive results of using compressed natural gas for fuelling public transport buses, in terms of road emission of - in particular - nitrogen oxides, as proved by tests, also in other aspects the use of methane fuel is reasonable. This applies particularly to compressed biomethane used instead of $\mathrm{CNG}$, with $\mathrm{CO}_{2}$ emission in the life cycle is almost null. Because of those aspects the use of vehicles fuelled with methane (CNG, LNG and biomethane) in bus fleets is reasonable.

\section{References}

1. M. Bajerlein, L. Rymaniak, P. Swiatek, A. Ziolkowski, P. Daszkiewicz, M. Dobrzynski, Experimental and Applied Mechanics 518, 108-113 (2014),

DOI: 10.4028/www.scientific.net/AMM.518.108

2. J. Merkisz, M. Bajerlein, P. Daszkiewicz, Lecture Notes in Information Technology 13, 106-113 (2012)

3. P. Lijewski, J. Merkisz, P. Fuc, A. Ziolkowski, L. Rymaniak, W. Kusiak, European Journal of Forest Research 136, 153-160 (2017), DOI: 10.1007/s10342-016-1015-2

4. J. Merkisz, S. Tarkowski, Eksploatacja i Niezawodnosc - Maintenance and Reliability 2, 5058 (2011)

5. Directive 2005/55/EC of the European Parliament and of the Council of 28 September 2005 on the approximation of the laws of the Member States relating to the measures to be taken against the emission of gaseous pollutants from positive ignition engines fuelled with natural gas or liquefied petroleum gas for use in vehicles. Official Journal of the European Union L 275/1

6. Regulation (EC) No 595/2009 of the European Parliament and of the Council of 18 June 2009 on type-approval of motor vehicles and engines with respect to emissions from heavy duty vehicles (Euro VI) and on access to vehicle repair and maintenance information and amending Regulation (EC) No $715 / 2007$ and Directive 2007/46/EC and repealing Directive 80/1269/EGC, 2005/46/EC and 2005/78/EC. Official Journal of the European Union L188/1

7. K. Brzozowski, J. Nowakowski, Eksploatacja i Niezawodnosc - Maintenance and Reliability 4, 56$62(2011)$

8. Commission Regulation (EU) No 582/2011 of 25 may 2011 implementing and amending Regulation (EC) No 595/2009 of the European Parliament and of the European Parliament and of the Council. Official Journal of the European Union L167/1
9. P. Bonnel, M. Weiss, A. Provenza, 8th Annual SUN Conference (Ann Arbor, 2011)

10. www.bluesolution.pl (2012)

11. J. Merkisz, J. Pielecha, S. Radzimirski, Springer Tracts on Transportation and Traffic 4, 67-90 (2014), DOI: 10.1007/978-3-319-02705-0_4

12. E. Król, M. Flekiewicz, Nafta - Gaz 7-8 (1997)

13. J. Merkisz, J. Pielecha, Springer Tracts on Transportation and Traffic 8, 69-92 (2015), DOI: 10.1007/978-3-319-15928-7_7

14. Sensors SEMTECH-DS, On Board Vehicle Emissions Analyzer (2012)

15. The role of natural gas and methane in the fuel mix of the future in Germany (Berlin, 2010) 